\title{
MANAS EPOSU MENEN CUSUP BALASAGINDIN KUTADGU BILIG DASTANINDA ADAM UKUGU CANA ADAM ADEBİ MASELELERINIIN ÇAGILDIRILIŞI*
}

\author{
Kaliya KULALIYEVA**
}

$\ddot{O} z$

İnsanoğlunu iyi yüreklilikle ve insancıllıkla ünleyen Manas destanı gibi Yusuf Balasagın'ın Kutadgu Bilig destanı da insanlara karşı saygılı olmaya, insan haklarını korumaya, değerli bir insan olmaya çağıran destandır.

Manas destanında başkahramanlar olan Manas, Koşoy, Bakay, Almambet, Cakıp, Koňurbay, Kanıkey'in karakterleriyle insanlığın millî ve evrensel ahlaki değerlerine ait özelliklerin yansıtıldığını görebiliriz.

Cengiz Aytmatov'un Manas destanı, Kırgız ruhunun zirvesidir dediği gibi söz konusu destan, Kırgızlar için bir ebedi enerji kaynağı sayılır. Yusuf Balasagın'ın Kutadgu Bilig eserinin hemen hemen her satırında da aynı düşünceyi görebiliriz.

Anahtar Sözcükler: Destan, şiir, insancıllık, ahlak, adalet.

\section{THE PROBLEMS OF HUMAN RIGHTS AND COURTESY IN EPIC MANAS AND KUTADGU BILIG (PROSPEROUS KNOWLEDGE) BY JUSUP BALASAGYN}

\begin{abstract}
In my article I would like to draw some parallels of the ideals of epic "Manas" with J.Balasagyn's Kutadgu Bilig where faithfulness, virtuousness, and humaneness and respect for human rights are described.

In epic Manas the humanistic morals and mankind peculiarities are given through the main epic heroes like Manas, Koshoi, Bakai, Almanbet, and Kanykei.

As Ch. Aitmatov noted the epic Manas is the most treasured expression of the national heritage of the Kyrgyz people. So it is the great pride and dignity for Kyrgyz nation. In "Kutadgu Bilig" by J. Balasagyn all human values are described as well and can be found in every two lines of this poem.
\end{abstract}

Keywords: Epic, poem, humaneness, courtesy, fairness.

\section{Kirişüü:}

Düynölük adabiy kazınada öz ordu bar, epikalık çıgarmaçılıktın mıktı ülgülörü bolgon, Manas eposu menen Kutadgu bilig dastanı folklorist menen adabiyatçı, filosof menen tarıhçı, etnograf menen geograf, politolog menen sotsiolog calpıbızdın aldıbızga aktualduu problemalardı koyup, ar taraptan tereñ izildöönü talap etüüdö. Manas eposunun ideyası, körkömdük özgöçölüktörünö baylanıştuu epostu ar taraptan izildöögö algan emgekter XIX kılımdın ekinçi carımınan baştap bügünkü küngö çeyin üzgültüksüz carıyalanıp kelüüdö.

\footnotetext{
* Bu makale Kırgızistan'ın başkenti Bişkek’te 22-23 Ekim 2014 tarihleri arasında düzenlenen “Türk Dünyası Vatandaşlığı Çalıştayı"nda sunulan bildirinin gözden geçirilmiş şeklidir.

** Dr.; Kırgızistan-Türkiye Manas Üniversitesi, kalia.kulalieva@gmail.com.
} 
"Manas" eposunan üzündülördü kagaz betine tüşürüp, başka tilderge kotorup caryaloodo, izildöödö, taanıtuuda V. Radlov, Ç. Valihanov, M. Auezov, I. Abdırahmanov, V. Jirmunskiy, E. Polivanov, A.Petrosyan, B. Yunusaliyev, S.Bogdanova, S. Musayev, E. Abdildayev, R. Kıdırbayeva, F. Türkmen, E. Gürsoy-Naskali, N. Yıldız sıyaktuu okumuştuulardın koşkon salımı zor.

Sayasiy-sotsialdık, pedagogikalık, filosofiyalık tüşünüktördün cıyındısı bolgon Manas eposunun kırgız elindegi barkı kanday bolso, calpı türk elderi üçün oşondoy ele baadag1 C.Balasagındın Kutadgu biligine baylanıştuu respublikada gazeta-curnaldardın betterine dastandın ideyalık-körkömdük özgöçölügün analizge algan, oşonun tegereginde, calpı dastan cönündö izildöölör, oy-pikirler carıyalanıp kelüüdö. Akademik V. Radlov tarabınan algaç izildenip, transkriptsiyalanıp nemis tiline kotorulgan bul çıgarma kiyin köptögön okumuştuulardın kızıguusun tuudurgan. Çıgarma tuuraluu maalımat S. E. Malovdun Pamyatniki drevnetyurkskoy pismennosti degen emgeginde da berilgen (Malov, 1951). Kutadgu bilig dastanının tili, maanisi, körkömdük özgöçölüktörü boyunça izildööçülör V. Radlov, S. Malov, A. Valitova, E. Bertelstin emgekteri, kırgızstandık okumuştuular A. Altımışbayev, S. Musayev, K. Artıkbayevdin izildöölörü, pikirleri cana emgekteri o.e. cakında ele carıyalanıp basmadan okuu kuralı katarı çıkkan tarıhçı Z. Eraliyevdin (Eraliyev, 2000), adabiyatçı A. Abdırazakovdun (Abdırazakov, 2008) emgekteri bizge belgilüü. C. Şeriyevdin (Şeriyev, 2000) Bayırkı adabiyat tarıhı, cogoruda atı atalgan A. Abdırazakovdun Cusup Balasagın cana anın Kutadgu bilig dastanı degen emgekterinin basmadan çıgışı Cusup Balasagındın murasın okup üyrötüügö karata casalgan ilgeri araket katarı karalışı kerek.

Koñşu mamleketter Özbekstan menen Kazakstanda Kutadgu bilig dastanına kızıguu 1960-c1ldarı ele payda bolgon. N. Mallayev (Mallayev, 1965), B. Tuhliyev (Tuhliyev,1983), A. Egeubayev (Egeubayev, 1998), N. Kelimbetovdor (Kelimbetov, 1991) Kutadgu bilig dastan1 boyunça türdüü izildöölörün carıyalaşkan. Kutadgu bilig dastanı türkiyalık okumuştuular tarabınan izildenilip kelüüdö. A. Dilaçardın Kutadgu bilig incelemesi (utadgu biligdi taldoo) (Dilaçar, 1995) attuu kitebi C. Balasagın caşagan doordu, dastandın tilin, temasın, ideyasın, andagı kaarmandardı kenen izildöögö alıp, ayrım sözdördün kotormosun berip, dastandı taanıtuuda çoñ rol oynogon. Bul emgek Türkiyada üç colu (1972, 1988, 1995 - cıldar) basılıp çıkkan. Oşondoy ele R. Arattın (Arat, 1991), dastandı izildöögö koşkon salımdarın aytpay ketüügö bolboyt. Rahmeti Arat "Kutadgu biligdin" üç nuskasın (Gerat, Fergana, Kair köçürmölörü bizge belgilüü) taldap, tekstin arab alfavitinen azırkı türk alfavitine transkriptsiyalagan cana azırkı türk tiline ilimiy kotormosun casagan. Kol cazmalardı okup 
catkanda kezdeşken kıyıçılıktarın atap, kolunan kelişinçe, tekstti öz kalıbında berüügö araket casaganın belgilegen.

Mından tışkarı, dastandın tildik, tarıhıy, sayasiy-sotsiologiyalık, pedagogikalık, madaniy, filosofiyalık özgöçölüktörün iliktöögö algan (Ercilasun, 1984; Kara, 1998; Kazmaz, 2000; Akyüz, 2002; Mahmut, 1987; Fındıkoglu, 1938) c.b. kitepteri ar türdüü c1ldarı basmadan çıarılgan.

Epos menen dastandın ideyalık-körkömdük özgöçölügün izildegen ar türdüü emgekter calpısınan köp ele carıyalanganın belgilöö menen, Kutadgu bilig dastanı boyunça izildöölör respublikalık masştabda Manas eposuna salıştırmaluu abdan az cana okurmandarıbızdın köbünö bul dastandın maani-mañızı cetkiliktüü daracada tüşünüksüz ekendigin moyunga alışıbız kerek. Oşondoy ele, bul dastandın Manas eposu menen salıştırıp izildöö cagı takır bolbogonun belgilöö menen epos menen dastandagı kılımdardı karıtkan elibiz menen koşo caşap kele catkan, curtubuzdun cürögünün tereñinen tünök tapkan, asıl oy-ideyalarının uçurubuzda da aktualduu, maanilüü bolup catkanı çındık. Koomubuz özgörüp, özübüzdün köz karandısız, egemendüü mamleketibizde caşap catıp mamleketibizdin tarıhın, elibizdin çınıgı madaniyatın, adabiyatın üyrönüüdö eñ maanilüü bulaktar bolgon körköm çıgarmalardın ar taraptan izildenişi, eldin, mamlekettin tarıhındagı ulam cañı baraktardın açılışına kömökçü boloruna işengibiz kelet.

Bul makalada epos menen dastanda adam ukugun korgoo, adam adebi menen 1ymanı cönündögü maselelerdin çagıldırılışındagı calpılıktar iliktöögö alındı. Bul çıgarmalarda bardık adamdardı teñ körüü, bardıgına alardın mümkünçülügünö caraşa cük artuu, adamdardı kordoboo, koldon kelse, el-cer üçün iştöö; keleçek muundun kamın körüü; uluunu sıyloo, kadırloo; kiçüünü ızattoo sıyaktuu oylordun parallel çagıldırılganına kübö bolobuz.

Eposton misaldardı keltirüüdö körkömdügü, kölömü boyunça da başka varianttardan ayırmalangan klassik manasçılarıbız Sagınbay Orozbakov menen Sayakbay Karalayevdin varianttarı paydalanıldı. Al emi Kutadgu bilig dastanın iliktöögö aluuda T. Kozubekovdun (Balasagın, 1993) kotormosundag1 1993 -c1lı kayradan basılgan Kuttuu bilim dastanınan misaldar keltirildi. Bul kotormonun kançalık deñgeelde originalga cakındıgı bar cana anın durus, buruş caktarın izildöö özünçö bir emgekti talap kılat. Bul maselege baylanıştuu kenenireek maalımattı Nazgül Turdubaeyvanın emgeginen (Turdubaeva, 2006), Lira Üsönakun kızının Cusup Balasagındın "Kutadgu bilig çıgarmasının kırgızça, türkçö cana kıtaylık kırgızdardagı kotorulgan variyanttarın salıştıruu” (Lira Üsönakun kızı, 2009, 55-b.) degen makalasınan taanışa alasızdar. 


\section{Adilettüülük - adam ukuktarının korgoluşunun bir belgisi katarı:}

Kutadgu bilig tereñ gumanizm menen sugarılgan çıgarma ekendigi baarıbızga maalım. Sen adamsıñ, adamga paydaluu bol, eliñ üçün işte, koluñan kelgen cakşıllıktı k1l, adamdı kordobo, anın ak emgegin baala, ömür ötküçö eliñe, adamdarga kızmat ötö degen sıyaktuu ideyalar dastanda ulam-ulam türdüü cagdaylarda, şarttarda basa belgilenip oturat. Az gana misal keltirip körölü:

3408 El üçün iştebegen - ölük adam,

Ölük bolboy, küç barda işte abdan.

(Balasagin, 1993, 271-b.)

3370 Aytçı sen, adamdıktın paydası emne,

Natıycasın ömürdö el körbösö?

(269-b.)

5161 Baalagın tirüülüktü elge arna,

Büt ömürdü kıpınday özüñ alba.

(389-b.)

5162 Kerektüünü iştegin, kündör bütpöyt,

Atkargın mildetiñdi, ömür kütpöyt.

$$
\text { (oşol bette) }
$$

5163 Conuña öz eliñdin cügün artkın,

Sak cana oyluu bolup, alga baskın.

$$
\text { (oşol bette) }
$$

Filosof A. Bekboyevdin sözü menen aytkanda dastan:

(...) oyçul-akın Cusuptun filosofiyalık kredosun kıskaça kvietizmden - gumanizmge dep tuyundursak bolot, antkeni al özünün okuusunda zamandaştarın, kiyinki urpaktarın bütündöy adamzattı poetikalık formadagı sıykırduu saptarı menen orto k1lımdag1 ofitsialduu diniy ideologiyanın negizgi cobolorunun birinen b.a. caşoo-turmuştun açuu-tattuusuna kayıl, kaydiger karap, caratkandın gana ırayımına işenip, anın erkine baş iyip tiriçilik kıluunu talap kılgan kvietizmden çettep, ömürdü, caşoonu, insand1 kadırlay-barktay, süyö bilüügö ündögön gumanizmge çakırat (Bekboyev, 1993, 27-b.).

Epikalık çıgarmaçılıktın mıktı ülgüsü bolgon bul eki çıgarmadan alçu sabak köp ekenin eskertüü menen, epos menen dastandagı adam ukugu, adebi cana 1yman maselesinin çagılış özgöçölüktörünö könül burmakçıbız. Epostogu Manas çıgarmanın baş cagında bir üydün erke balası, andan soñ bir curt atası bolot. Oşol ele uçurda Manas - coldoşu üçün canın ayabagan dos, duşmanına cooptu katıra kaytargan kas, Koşoy, Bakay sıyaktuu abalarına sıy körsötkön ini, 
kiçüülördü erkin, köz karandısız caşoo üçün küröşkö ündögön aga, Kanıkeydey akılduu ayalga işeniçtüü car cana elinin birdikte, erkin mamlekette caşoosun eñsegen - el uulu. Al adamdardın ukugun korgop, elinin beypil caşoosun oylogon akılduu başkaruuçu. Al aksakaldardın nasaatın ugat, özünün tuura iş kılıp catkandıgın başkalarga tüşündüröt. Epostu okugan adam kırgızdardın biri-birine mamilesi, baylanışı, adep - ahlagı, ıymanı kançalık daracada suktanarlık bolgondugun körüp, tañ kalbay koyboyt. Manastın öz eline, çoroloruna, cakındarına, tuugandarına, duşmandarına karata casagan mamilesinen anın adebi, ıymanı kançalık daracada cogoru ekendigi anıktalat.

Cusup Balasagın öz çıgarmasında askerbaşının sapattarın sanoodo birinçi kezekte adilettüülüktü atagan. Adilettüülük, çındık, kalıstık öküm sürbögön cerde asker işinin cürüşü ötö naçar bolot. Cookerler adiletsiz çeçimderdin kabıl alınışına naarazı bolup öz ökümdarlarına karş1 çıgışı mümkün, al emi asker çoñ küç ekendigi baarıbızga maalım. Epostogu tömönkü saptar Manastın soguş uçurunda askerin başkaruuda körsötkön adilettüülügünün birden bir kübösü bolo alat:

Kılıç çapay, ok atpay,

Kiyınsinip caa tartpay,

Aldırıp salgan kim deysiñ,

Albañar cirık iynesin,

Ne kılasıñ kalmaktın

Ezelden c1ygan düynösün.

Bayınan soyuş alsañ da

Koñşusun koyup salıñar.

(S.O., M. 2-k., 44-b.)

Manastın maksatı talap - tonoo, bayıp ketüü, eldi ezüü, öz üstömdügün ornotuu emes, al öz cerin duşmandardan boşotup, elinin erkindikte caşoosun kamsızdap, öz mamleketin çıñdoonu oylogon. Anın adilettüülügünün dagı bir çagılışı katarı al çaap, basıp algan cerlerine oşol eldin içinen kalk kaalagan birin han, bek kılıp kötörüp, andan arı c1lıp oturgan. Bizdin kündün tili menen aytkanda, biylik cergiliktüü başkaruu organdarına ötkörülüp berilgen. Manastın adilettüü han cana askerbaşı bolgonuna epostogu köptögön okuyalar menen epizoddor kübö bolot. Al Ala-Too, Anciyanga saparga çıgarda adilettüülük menen elge keñeş salıp, öz curtuna tömönküdöy sözdör menen kayrılat:

Körbögön cerge bargın dep,

Zordobosmun silerdi,

Altayda ata - ceriñer, 
Anciyanga baruuga

Bizge uruksat beriñer,

Kalganıñar kalıñar,

Kaalaganıñ barıñar,

El başçısının kıraakılık, akılmandıgı:

Kalganım kalsa Altayda,

Karmaşar bolso kitayga

Kalkıma kiyin çoñ payda.

(S.O., M. 4-k., 152-b.)

- degen saptarda çagıldırılat. El başkargan kişi elinin keleçegin dayıma oyloş kerek. Mamleket başkaruuda çeçim kabıl alardan murun el menen keñeşip, el içindegi aksakaldardın pikirin ugup, sunuştarın eske aluu çıyaktuu col-cobolordun caşoosu al mamlekettin paydasına gana çeçilçü.

Adamdarga adilettüülük menen mamile kıluu adeptüülüktün bir belgisi bolup sanalat. Adilettüülük menen el başkargan Manas öz eline, askerine - cölök, tayanıç, al emi duşmandarına - korkunuçtuu coo, ayabaganday akılduu, küçtüü kas. Manas maanilüü maselelerdi çeçüüdö, kızmattardı bölüştürüüdö, cooptuu işterdi biröögö artuuda, duşmandardın adiletsizdigin cazaloodo eñ adilet, eñ tuura coldordu tandap alat. Adilettüü boluu kerektigi cönündögü ideya «Kutadgu biligde» da ulam-ulam kaytalanıp, adilet boluu bardık nersenin başı degen sıyaktuu ideyalar da cok emes. Ölör aldında Aytoldu Elikke kereez kaltırat:

1366 Adilet bol kataaldıkka kabılba,

Eldi kubant, emgektenip cañılba.

$$
\text { (140-b.) }
$$

1372 Men ölgön soñ, ey Elik, tetik bolgun,

Boş ötkörüp mezgildi kordobogun.

$$
\text { (oşol bette) }
$$

1327 Dos-tuugandı ala cür cakın kılıp, Kiçüügö, uluuga da bolgun silık.

$$
\text { (137-b.) }
$$

Bul bir bek bolgon, ce el biylöönü köksögön adam üçün gana aytılgan söz emes, bardık men adammın degender, adilettüülüktü adeptin bir cagı katarı bilişi kerek. Eger al adam mamleket başında tursa, anda adilettüülük eñ birinçi sapatka ötöt. Antkeni adiletsiz mamilenin 
natıycasında koomgo, mamleketke, bütkül adamzatka eñ kerektüü adamdardı cok kılıp aluu korkunuçu tuulat.

Dastanda ar bir kesip eesine kanday adamdık sapattagı kişi tuura kelerin aytuu menen avtor, bul kesipterdin koomdogu ordu, mamlekettegi rolu kançalık daracada ekendigin belgilegen. Avtor bul kesiptin eelerine kanday mamile kıluu kerektigine özünçö toktolot. Algaç bardık adamdarga cakşı mamilede bolup, alardı kemsintpöö, alardın ukugun saktoo, alar menen esepteşüü kerektigin belgilegen Cusup Balasagın, dastandın logikalık ıraattuulugun buzbastan, kiyin gana ar bir kesip eesine kanday mamilede boluusu kerektigin aytat. Algaç calpı adamdarga mamile kıluudagı başk1 özgöçölük tömönkü saptar arkıluu berilse:

4276 Cakş1lıkta dayıma caşaym deseñ,

Adamdı kemsintpegin, tepsebe sen.

(329-b.)

4284 Kişinin eñ mıktısı ası1 adam,

Adamdıktı eç kaçan unutpagan.

(oşol bette)

Kiyin kelgen kesip eelerine mamile k1luunun tartibi da al kesiptin koomdogu maanisine caraşa çıgarmada orun alganday. Misalga alıp karap körsök, avtor, kesip eelerinen eñ algaç ele daanışman, ilimpoz adamdarga kanday mamile kıluu kerektigine toktolot.

4341 Dagı bir adamdar bar bilimi mol,

Bilimi calpı curtka körsötöt col.

$$
\text { (333-b.) }
$$

4342 Kadırlap, slyluu bolgun alar menen,

Azb1-köppü bilimin algınıñ sen.

$$
\text { (oşol bette) }
$$

4346 Bolboso kokus bular bu düynödö,

Cerde cemiş mol bolup önböyt ele!

(334-b.)

4347 Bilimi daanışmandın elge carık,

Carık bolso tündö da coluñ anık.

$$
\text { (oşol bette) }
$$

4353 Alar çını otordo - erkeç sımal,

Baştasa koydu colgo alıp çıgar.

$$
\text { (oşol bette) }
$$

4354 Bular menen cakşı bol, ıntımak tap, 
Eki düynö tabasiñ ketpegen bak.

(oşol bette)

Bilimdüülör dayıma aldıñkı kişilerden bolorun aytuu menen tuura coldu el-curtka alar körsötörün belgilegen Cusup Balasagın, ilimpozdor ıntımak taap, kadırlap-sıylap alçu adamdar ekendigin, taamay aytkan.

El içindegi darıgerlerdin adamdar üçün maanisi zor ekenin:

4355 Adamdın türlörü bar, dagı kança,

İşteri, mansabı da başka-başka!

(334-b.)

4356 Taanıp al arasınan darıgerdi,

Ayıktırat keselden alar eldi.

(334-b.)

4357 Oylosoñ bular saga kerektüülör

Bularsız coluñ bolboyt basıp cürör.

(334-b.)

4360 Darıgerdi sıylagın, dostoşo cür,

Elge kerek, aytkanın atkara bil.

$(335-b$.

- degen saptar menen belgilese, eñ bayırkı kesipterdin biri bolgon akındık cönündö tömönküdöy saptar bar:

4392 Emi biz kep baştaylı akındardan,

Adamdı ar k1l aytkan asıldardan.

$$
\text { (C. B., 73-b.) }
$$

4393 Mukam söz birde çaçtay cumşak, nazik.

Birde al kılıç öñüü ötöt kesip.

$$
\text { (oşol bette) }
$$

4396 Mazaktap mensingendi akın cigat,

Belgisiz candı maktap maalım kılat.

$$
\text { (oşol bette) }
$$

4399 Andıktan akındardı baalay bilgin,

Ardaktap köñülün al baarın bergin.

(oşol bette) 
Akındar da koomdo maanilüü rol oynorun, alar maktasa adamdın atagı aalamga tarap, camandasa azapka kaları çındık, oşonduktan alarga cakın turup, sıy körsötüş kerektigin aytuu menen Cusup kezeginde el, biylik, mamleket işinde akındık kesiptin ordu azırkıdan alda kança başkaça bolgonun, el alardın sözünö maani berip, alarga işenip, alardın ünü biyliktegilerdi da sestentip, çoçutup kelgenin belgileyt.

Al emi dıykançılık, soodagerlik, malçılık kesipti arkalagan adamdarga kanday mamile kıluu kerek cana emne üçün ekendigin akın tak, taamay aytılgan saptar arkıluu berip, mamlekettin ekonomikalık, sotsialdık, madaniy caktan önügüşü soodagerlik kesipti arkalagan adamdardın iş-araketine baylanıştuu bolup, alarga da cakşı mamile kıluu kerektigin akın bul saptar menen beret:

Açık bolup, kabıl al alar kelse,

Cakşı atagıñ taralat alıs cerge!

(C.B., 340-b.)

İlimpozdordon tartıp malçılık, ustaçılık menen alektengen kişilerge çeyin mamile kıluuda adamkerçiliktüülükkö çakırgan Cusup Balasagındın bul dastanı adam emgegin baaloo, anın koomdogu ordun sıyloo, ukugun korgoo, kemsintpöö, taarıntpoo, alına caraşa cük artuu kerektigi cönündögü ideyanı car salat. Eposto da, dastanda da aç közdük, sarañdık, biylikke, baylıkka aşkere umtuluuçuluktun adepke catpastıgı açık aytılat.

2. Bolgongo kaniet kıluu, keñeşip iş cürgüzüü, uluunu urmatto - adeptüülüktün belgileri katarı:

Ar nersege topuk k1luu, bolgongo kaniettenüü, biyliktin, baylıktın tübölüktüülügünö işenböö kerek degen ideya bul dastanda ulam eskertilip olturat. Odgurmış attuu kaniettin simvolu bolgon körköm obrazdı dastanga kirgizüü menen avtor adam balasın dagı baaluu bir sapat - adamkerçilikten çıkpoogo, bolgongo kaniet kıluuga, ınsapka çakırat. Kaniet kılıp caşabasa, adam camandıkka canaşarı anık, andıktan bul simvol-obraz menen kaniet kıluu printsibi mamleketti başkaruuda başkı talaptardan ekendigin eskertet. Kaniet kılbagandık eldi cakırçılıkka, turmuştun oordop, adamdardın biri-birinin akısın cep caşoo şartına köndüröörü, bul bolso, mamleket üçün ötö zıyanduu korkunuç tuudura turganın avtor bilgiçtik menen aytat.

Dostuk, birdikte keñeşip iş cürgüzüü, adilet mamile k1luu, kaniet kıluuda başkaruuçu özü birinçi ülgü boluu menen kızmat ötöösü mamlekettin avtoritetinin ösüşünö gana alıp kelerin Cusup Balasagın mından 10 kılım murun caratkan emgeginde irga koşup dañazalagan eken. «Bir nersege cetişem deseñ nısaptuu bol» degen pikirdi aytuu menen Cusup Balasagın tüz ele bizdin küngö kelip, azırkı başkaruuçularga da nasaat berüüdö. Bul nasaattın azırkı kündö 
başçılar, cetekçiler tarabınan ugulup, tuyuluşu mamleket, koom üçün ötö maanilüü ekendigi baarıbızga tüşünüktüü.

Eposto baş kaarmandar Manas, Bakay, Almambetterdin kandıkka, başkaruuçulukka umtulup, cutunganın biz körböybüz. Bardık uçurda biylik başına sunuş kılıngan baş kaarmandar iştin coopkerçiligin sezüü menen köpçülüktün çeçimi arkıluu kalk kanı, kol başı, col başı bolup şaylanışat. Manastın kan bolboym dep kaçkanı S. Orozbakovdun variantında mındayça süröttölöt:

Kaçkan menen bolboston

Kabilan Manas balanı

Kamalap karmap alganı,

Koyuñar dese bolboston,

Alıp kelip Manast1

Ak terdikke salganı,

Kanıbız dep dürküröp,

Kan kötörüp alganı.

(S. O., M., 1-k., 241-b.)

Elge, aksakaldarga, özünön uluularga keñeşip iş k1luu, alarga ayar mamile casoo kırgızdarda adeptüülüktün özgöçö çagılışı bolup sanalat. Keñeşip iş kıluu iygilikke alıp kelerin dastan tömönküçö bayandayt.

5653 Keñeş menen ar adam colun tüzöyt,

Keñeşpegen adamda kırsık küçöyt.

(C.B., 420-b.)

5658 Ugup al keñeşçinin aytkan sözün,

Keñeş uksañ , algalayt senin işiñ.

(oşol bette)

Ar bir maanilüü iş eposto el menen keñeşip çeçilet. Eldin keñeşin ukpay, atasının aşın Manas kele elekte baştagan Bokmurundun abalı «Kökötöydün aşınan» bizge belgilüü. Dagı başka misal, Manas elge, altı kanga keñeş salıp, altı kandın biriñer kan bolgula dese, eç kimisi unçukpayt, oşondo, kırgız koluna kan bolup Bakay şaylanat, al emi col biyligi:

Baarıñarga ep bolso,

Uşu coldun biyligin

Almambetke berelik.

Körgö tüşsö tüşüügö. 
Kölgö tüşsö, tobokel.

Köt cagınan süzüügö,

Daban aşsa aşuuga

Şamalga uçsa uçuuga.

(S. O., M., 4-k., 68-b.)

- dep, Almambetke berilet.

Manas eposundagı Manastın obrazına baylanıştuu adeptüülüktün başka bir çagılışı katarı anın agaları, abaları, curt başı ak sakaldarga casagan mamilesin karoogo bolot. Manastın açuusu çukul, al bir nersege açuulansa eç kimdi könülünö albayt, taş-talkanın çıgarıp baarın kıyratat, sabayt, kubalayt. Birok dayıma ele oşente berbeyt. Adiletsizdik menen iş casalgan bolso, ce namıska tiyçü söz aytılsa, özünö keñeş menen kayrılgandarga cok dep ayta turgan bolso, sözsüz türdö, adeptüülük menen, emne üçün uşunday çeçim kabıl alganın tüşündüröt. Misalı, Maanikerdi bergile dep Koñurbay talaşkanda, Koşoy bereli dese, Manas:

Attigine abake,

Ak1lıñı kanake?

Senden bölök biri aytsa,

Albas belem canın dep,

Tökpös belem kanın dep!

Camandikka kiybagan

Koşoyluktan kaldıñ dep.

Oyronuñ Manas ölgöndö,

Oşondo tartuu berseñçi,

Azır menin barımda

Manasım bar dep aytsañçı!

(S. O., M. 3-k., 140-b.)

- dep, bügün Maanikerdi bersek, erteñ Akkulanı surarın aytıp kelip:

Maaniker berdi degiçe,

Manastı öldü deseñçi!

Batañdı kıla kelseñçi.

(S. O., M. 3-k., 141-b.)

- degen coobun aytat. Oşondoy ele duşmanga tartuu bereli degen Cakıpka (S.K., M., 1k., 1984, 88-b.), uruşka kirbey keteli degen Baltaga (oşondo 135-b.) uruşup catıp ölsöm da, men namıstı berbeym dep, karşı1ık körsötüüsünün sebepterin negizdegen. Al emi Neskaranın 
adiletsizdigine karşı, eli üçün küygön Manas, açuu coop kaytarat. Kazandagı etti talap, Baymırzanı sabagan Neskaraga öz cazasın beret.

Kara caak kamçını

Karmap alıp imerip,

Oşondo Neskaraday baatırdı

Töbögö tartıp ciberip,

Malakay uçtu çırkırap,

Ötögöt taşı bırkırap,

(S. K., M. 2-k., 38-b.)

Manastın Neskaraga mınday mamile kıluusunun sebebi bar. Eposto baş kaarman Manastın ar bir araketine tüşündürmö berilet.

Al emi Manastın dosu Almambettin adamkerçiligi köp uçurda tañ kalarlık. Çubak Beecinge çalgınga men barat elem dep çatak salganında Almambet aga sabırduuluk menen tüşündürüp, anın oyunun tuura emestigin tömönküçö aytat:

Oylosoñ bolo sen, Çubak,

Oloñdogon kizitalak,

Men Beecindi çalam kim üçün?

Arttag1 kalıñ el üçün,..

Tosmosu katuu kıtaydın,

Topuragı uçup küyöt dep,

Tozogu saga tiet dep,

Toskon colum kim üçün?

Tozoktuu Çubak, sen üçün!

(S. K., M. 2-k., 93-b.)

Uluunu sıyloo, urmattoo, kiçüünü 1zattoo adeptüülüktün, özgöçö kırgızdarda, başk1 çagılışı ekenin babalardan kalgan Karının sözün kapka sal, Karısı bardın - 1rısı bar, Karı kelse aşka, caş kelse - işke degen makaldar dalildep turat. Eposto da Manastın özünön uluularga sıy körsötüüsü caştarga eñ sonun ülgü bolorluk türdö berilgendigi bizdi abdan kubandırat, sıymıktandırat. Misalga alsak, Manas Kökötöydün aşında cambı atıp tüşürüp, andagı utkan baygesin Koşoygo tömönkü sözdördü aytuu menen tartuu kılat:

Abake munu algin dep,

Ak sakalduu karımsıñ,

Kasiettüü canımsıñ 
Mına uşunu algın dep,

Batañdı berip salgın dep.

(S. O., M. 3-k., 179-b.)

- dese, Koşoy kayradan:

Kaşıñdagı bir çaldı,

Karıp kalgan bir candı

Özüñdön aziz körbögün,

(S. O., M. 3-k., 179-b.)

Olcoñdu özüñö kaltırgın dep, aga karata 1zat körsötöt. Uluuga urmat, kiçüügö 1zat degen sözdün maanisi da uşunda catkanday. Oşondoy ele Çoñ kazatta kol baştagan Bakaydın kandıgın Almambetke suroodo Manas ötö akılmandık menen, abasının köñülün oorutup alboonu oylop, bul oyun tömönküçö bildiret:

Köñülünö albasa,

Aytt1 dep naalat kılbasa.

Aytkanım makul körsün dep,

Azırkı kandigin

Almambetke bersin dep,

(S. O., M. 4-k., 116-b.)

Munu ukkan Bakay tüşünüü menen kabıl alıp, tömönküçc̈ coop kaytarat:

Al Almambet arstand

Manastan da artık körömün,

Bir surasa al üçün

Miñ kaytara beremin.

Baatır Alma sultand,

Balamdan cakın körömün,

Başkarıp alsın askerin,

Baçımıraak cönögün.

(S. O., M. 4-k., 119-b.)

Cogoruda keltirilgen misaldar adamkerçilik, ayköldük, adam adebinin, ıymanının çagılışının cogorku çegi. Oşondoy ele Kökötöydün aşında Koñurbaydın salgan çatagınan korkkon Bokmurundun Koşoy abasına barıp, anın aytkanın ukpaganına ökünüp turgan ceri eposto minday saptar menen berilet: 
Aş berem dep kelippiz, aba,

Azaptı artık körüppüz, aba,

Acaldan murun ölüppüz, aba!

Uluunun tilin albadım, aba,

Emi ubaraga kalganım, aba!

Bilgiçtin tilin albadım, aba,

Aş beremin dep kelip

Bilçelik küçkö kalganım, aba!

(S. K., M. 2-k., 28-b.)

Bul saptarda uluu cana bilgiç degen sözdör sinonim katarı kaytalanıp kelip, aytılıp catkan arman, ökünüç sözdördün maanisin küçötüp, tereñdetip turat.

Uluulardı sıyloo cakşı1ık gana alıp kelerin «Kutadgu bilig» dastanı da kaytalap aytat:

4178 Kiçüülördün uluular sıyın köröt,

Uluuga kızmat k1lsanq bakit kelet.

(C.B., 323-b.)

4179 Uluulardı urmatta akılın uk,

Uluunun sözün uksanq - kutunq önöt!

(oşol bette)

4304 Uluularga urmat-sıy körsötö cür,

Özünq da kut tabasınq, oşonu bil.

(C.B., 330-b.)

Iyman menen ar namıs biri-birine cakın tüşünüktör. Epostogu Manas cana anın kırk çorosun biriktirip turgan nerse da adam ıymanı bolup sanalat. Alar biri ekinçisin satpayt, dayıma biri-birine cölök-tayak bolup, baarının maksatı el-cerinin boştondugun, köz karandısızdıgın korgoo. Başçıları Manas kaza bolgondon kiyin da anın çınıgı dostoru, çoroloru özdörünün baatırına, başçısına akırkı kızmat katarı Kanıkeydi karaan tutuunu başkı iş dep çeçişet. Alardın adebi, ıymanı başkaça boluuga col berbeyt. Bakay baş bolup, ölgöndön kalganı Kanıkeydi koldop, Manastın uulu Semeteydin törölüp, boygo cetişin çıdamsızdık menen kütüşöt.

Kutadgu biligde adamdardın cırgalç1lıgı üçün kızmat kılgan adilettüü mıyzam kabıl alıp, al mıyzamdı başkaruuçular özdörü saktap, adamdardın ukugun korgop, mildetterin tak atkarıp, kişiliktüü, adamkerçiliktüü bolgondo el baktıluu bolot degen oy bar.

453 Biylik menen uluuluk urmattalat,

Çındık menen ukuktu cürsö karmap. 
(C.B., 79-b.)

454 Biyligi cakşı bektin - maktoogo teñ,

Andan da - zañı artık elge bergen.

(oşol bette)

453 Baktıluu, elge ardaktuu ökümdarlar,

Egerde kişiliktüü bolso alar.

(oşol bette)

1458 Ökümdar! Adilettüü bolsun cazañ,

Sayasatı̃̃ camanbı - işiñ caman!

(C.B., 145-b.)

Adamkerçiliktüü boluu adeptüü boluunun dagı bir cagı ekeni bizge maalım. Eger adamkerçiliktüülük zañdın negizin tüzgön bolso, Manas eposundagı mıyzam - Manastın el menen keñeşip çeçken sözü, demek, Manastagı mıyzam - Manastın sözü, al emi Manas mıyzamdı adilettüülük, adamgerçilik, ayköldüktün printsipterin buzboo menen kabıl alganı bizge eposton maalım. Kutadgu bilig dastanındagı adam adebi, adam 1ymanı, ar namıs cönündögü, adam degen attın uluulugu tuurasındag1:

1598 Adamdigıñ asmandatat atıñdı

Adamdıgıñ carkıratat zatıñdı.

$$
\text { (C.B., 154-b.) }
$$

1599 Adam bolgun, ast1 ayban atanba, Abiyir bolboyt kıpınday da naadanda.

(oşol bette)

- degen cönököy saptarda tereñ oy catat. Sen birinçi adam bol, oşol atka tatıktuu bol deyt. Adamdın adamdıgı anın atın asmandatarı, carkıratarı cönündögü tak, taamay aytılgan sözdör, bardık nersenin adamda adamdık sapattın bolup-bolboşuna baylanıştuu ekenin kayradan esibizge salat. Manas ata öz ömürün «adam» degen atka tatıktuu caşap ötkönün azırkı uçur dalildöödö. Manas cönündögü dastan, anın elesi, obrazı, cogorku saptarda aytılganday, Manas bababız adam üçün, kırgız eli üçün cakşılıkka caralgandıgınan, azırkı küngö çeyin ar bir "men kırgızmın", "men adammın” degen atuuldun cürögündö caşap catat.

\section{Korutundu:}

Epostun da, Cusup Balasagın kaltırgan uluu dastandın da başkı teması, ideyası, mazmunu adam, anın caşoosu, anın caşoosunun mañızı bolup, muundan muunga almaşkıs muras katarı ötüp, azırkı küngö çeyin saktalıp kelgeni menen biz sıymıktanabız. Antkeni bul 
baba murastarında bütündöy türk elderinin (uruularının), anın içinde kırgızdardın bayırtadan berki madaniyat1, sayasatı, tarıhı, ilim-bilimi, düynö tüşünügü, filosofiyası, pedagogikası c.b. ötö keñiri planda çagıldırılgan.

Başkaruuçulardın adamdarga adilettüülük menen mamile kıluusu; karapayım kalktı kıyınçılık uçurda koldoosu, korgoosu, ayosu; elge mümkünçülügünö, küçünö caraşa cük artuusu alardın ukuktarının korgoluşunun bir belgisi katarı karaluuga tiyiş.

Bolgongo kaniet k1luu, el menen keñeşip iş kıluu, adamkerçiliktüü boluu, uluunu urmattoo, kiçüünü ızattoo degen türk elderinin ruhunun, madaniyatının, pedagogikasının negizin tüzüüçü ideyalardın bul eki çıgarmada parallel berilişi kiyinki muundarda bul sıyaktuu sapattardın kalıptanışına çoñ türtkü bolorun esten çıgarbay, bul murastardı caştarga okutuu, maani-mañızın tüşündürüü, ar taraptan izildöö dagı dele uçurdun aktualduu maselelerinen bolup kala bereri anık.

Bul eki çıgarmada adam adebi cana 1yman maseleleri menen katar, mamlekettüülük, mamleketti uyuşturuu, başkaruu ideyaları öz içine kamtıgan, mamleketti korgoo, elderdin birimdigin saktoo, anı buzboo, parallel çagıldııılganın baykoogo bolot, bulardın berilişteri da okşoş. Okşoştuktar calañ ele ideyalarda emes, calpı çagıldırılgan maselelerde emes, a tügül koldonulgan bayırkı kırgız til baylıgında da bar ekeni baykalat. Biz leksikalık okşoştuktarga toktolgon cokpuz, al aytpasa da tüşünüktüü. Birok poetikalık caktan bolgon ündöştük, okşoştuktardı açıp körsötüü, izildöö keleçekte atkarıla turgan işterden ekendigi talaşsız.

\section{Paydalanılgan Adabiyattar:}

ABDIRAZAKOV, A. (2008). Cusup Balasagın Cana Anın "Kutadgu Bilig” Dastanı: Okuu Kuralı. Bişkek: Cusup Balasagın Atın, Kırg. Ulut, Un-Ti.

AKYÜZ, H. (2002). Kutadgu Bilig'de Sosyopedagojik ve Siyasal Söylemler. Erzurum: Eser Ofset.

ARAT, R. (1991). Kutadgu Bilig. I. Metin, Ankara.

ARTIKBAYEV, K. (1999). Cusup Balasagın Cana Mahmud Kaşkardın Murastarı. Okuu Kuralı, Bişkek.

ASLAN, M. (1987). Kutadgu Bilig'deki Toplum ve Devlet Anlayışı. İstanbul: İstanbul Üniversitesi Edebiyat Fak. Yay., 3414.

BALASAGIN, C. (1993). Kuttuu Bilim. Kotorgon T. Kozubekov, - M.: "Nik".

BEKBOYEV, A. (1993). Kvietizmden - Gumanizmge / Cusup Balasagın Kuttuи Bilim. Kotorgon T. Kozubekov, - M., Nik, 27-b.

DİLAÇAR, A. (1995). Kutadgu Bilig İncelemesi. İstanbul.

EGEUBAYEV, A. (1998). Kicilik Kitab1. Ana Tili, 320 b.

ERALIYEV, Z. (2000). C. Balasagın Okuu Kuralı. Bişkek: İIMOP KGNU. 
ERCILASUN, A. B. (1984). Kutadgu Bilig Grameri - Fiil. Ankara: Gazi Ü. Yay., 33.

FINDIKOĞLU, F. Z. (1938). XI. Asırda Bir Türk Mütefekkiri ve Ahlaki Düşünceleri. Ankara.

KARA, M. (1998). Bir Başka Açıdan Kutadgu Bilig. Ankara: Kültür Bakanlığı Yay., 2031.

KAZMAZ, S. (2000). Hukuk ve Devlet Yönetimi Açısından Kutadgu Bilig (Kutadgu Bilig Üzerine Hukuki Bir İnceleme). Ankara: Türk Kültürünü Araştırma ve Tanıtma Vakfı Yay.

KELIMBETOV, N. (1991). Ecelgi Dogur Adabiyatı. Almat1.

MALLAYEV, N. (1965). Uzbek Adabieti Tarıhı. 1-Kitep, Taşkent.

MALOV, S. (1951). Pamyatniki Drevnetyurkskoy Pismennosti. AN SSSR, M-L.

MANAS. (1978). S. Orozbakovdun Variantı. I Kitep. - F.: Kırgizmambas, - 296 b.

MANAS. (1980). S. Orozbakovdun Variantı. II Kitep. - F.: Kırgizmambas, - 449 b.

MANAS. (1981). S. Orozbakovdun Variantı. III Kitep - F.: Kırgızmambas, - 346 b.

MANAS. (1982). S.Orozbakovdun Variantı. IV Kitep. - F.: Kırgızmambas, - 366 b.

MANAS. (1984). S. Karalayevdin Variantı. I Kitep. - F.: Kirgızmambas, - 248 b.

MANAS. (1986). S. Karalayevdin Variantı. II Kitep. - F.: Kırgızmambas, - 216 b.

ŞERIYEV, C. (2000). Bayırkı Adabiyattın Tarıhı. Bişkek - Oş.

TUHLIYEV, B. (1983). Poetika “Kutadgu bilig” Yusupa Balasagina. Moskva.

TURDUBAYEVA, N. (2006). Balasagın Cana Anın “Kutadgu Bilig” Dastanı (Dastandın Izildenişi Cana Kotormoloru). Bişkek: Biyiktik.

ÜSÖNAKUN KIZI, L. (2009). Caşagım Kelet, Caşagım: Irlar, Añgemeler, Ilimiy Makalalar Cana Eskerüülör. Bişkek: Biyiktik. 